\title{
Structural Study by High Resolution Transmission Electron Microscopy of Zirconia Nanoclusters.
}

\author{
M. I. Espitia-Cabrera*, V. G. Delgado-Arellano**, E. Calderón-Hernández*, H. Juárez-Medina***, \\ M.E. Contreras-García***. \\ *FIQ. UMSNH. Edif. "D”, C.U.,C.P. 58060 Morelia Mich. email:ieumich@yahoo.com \\ **CIDEM. Calzada Juárez 1446, Col. Villa Universidad, C.P. 58060 Morelia Mich.; IIM. UMSNH. \\ Edif. “U”, C.U., C.P. 58060 Morelia Mich. email:alvicyolx95@yahoo.com.mx \\ ***Instituto de Investigaciones Metalúrgicas, UMSNH. Edif. "U”, C.U., C.P. 58060 Morelia Mich. \\ email: juarezmh@hotmail.com, eucontre@,zeus.ccu.umich.mx.
}

\begin{abstract}
The recent development of nanostructured materials, needs processing technologies that allow to obtain physical-chemical stable nanoparticles ${ }^{[1]}$, the characterization techniques of this kind of materials needs the use of high resolution Electron Microscopy that allow to study the nanostructural morphology and defects, and to correlate them with the processing parameters. In this work, chemical techniques of solution-precipitation have been used, they allow to obtain molecular structured precipitates from which nanometric particles are easily obtained, keeping strictly their stability during the subsequent separation process. In this process is extremely important to employ methods that allow the best particles dispersion, so in this study, it has been proposed the use of microwaves, that change the kinetics of hydrolysis and condensation reactions enhancing the reactions rates and also helping the dispersion process ${ }^{[2]}$. It has been proved that the use of microwaves is highly beneficial for helping the sol-gel processing, principally because to its contribution to the mixed dispersion and thermal effects of the electric and magnetic fields applied to the sample by the microwave treatment ${ }^{[3]}$. It has been shown that those effects are evident in the microstructures obtained by TEM (Field Emission, Phillips TECHNAI 200 Microscope) of the $\mathrm{ZrO}_{2}$ nanoclusters which are uniformly spherical as it is shown in fig.1, the sizes of them are around the $300 \mathrm{~nm}$. The high resolution image fig.2, shows that the nanoclusters are polycrystalline and the size of these crystallites is about of the order of 6-8 nm. Some of them presented dislocations Fig.3, probably originated by the zirconia phase transformation during the thermal treatment of the obtained clusters. Fig. 4, shows the EDX microanalysis of the sample with only zirconia signals $(\mathrm{Cu}$ and $\mathrm{C}$ signals correspond to the grid composition).
\end{abstract}

Acknowledgments: The authors acknowledge to M. Ariosto Medina for his technical support in MET, and thank to CIC of the UMSNH, for the economical support in this research.

\section{References:}

[1] Limaye U. Amit and Helb J. Joseph (2002). Morphological Control of Zirconia Nanoparticles through Combustion Aerosol Synthesis. Journal of the American Ceramics Vol. 78,No.4,pp.11031106.

[2] Young Tae Moon, Do Kyung Kim, and Chong Hee Kim (1995). Preparation of Monodisperse Zr02 by the Microwave Heating of Zirconyl Chloride Solutions. Journal of the American Ceramics Vol. 78,No.4,pp.1103-1106.

[3] D. Agrawal, J. Cheng and R. Roy (2002). Microwave Processing of Ceramics and Materials in Single Mode E Fieldand H Field. In: International Conferences on Modern Materials \& Technologies (CIMTEC). pp 32. 


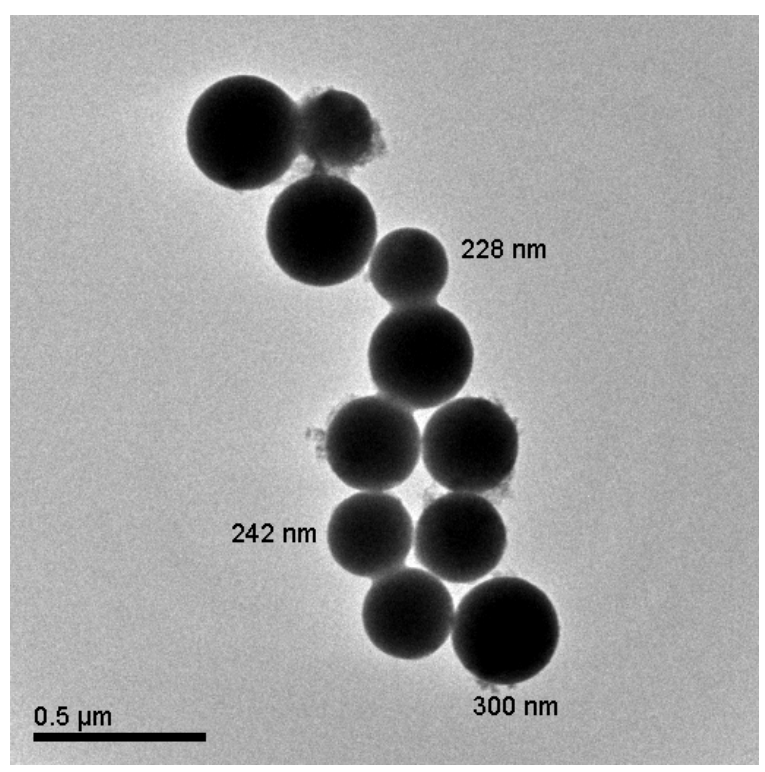

Fig.1. TEM image of $\mathrm{ZrO}_{2}$ nanoclusters.

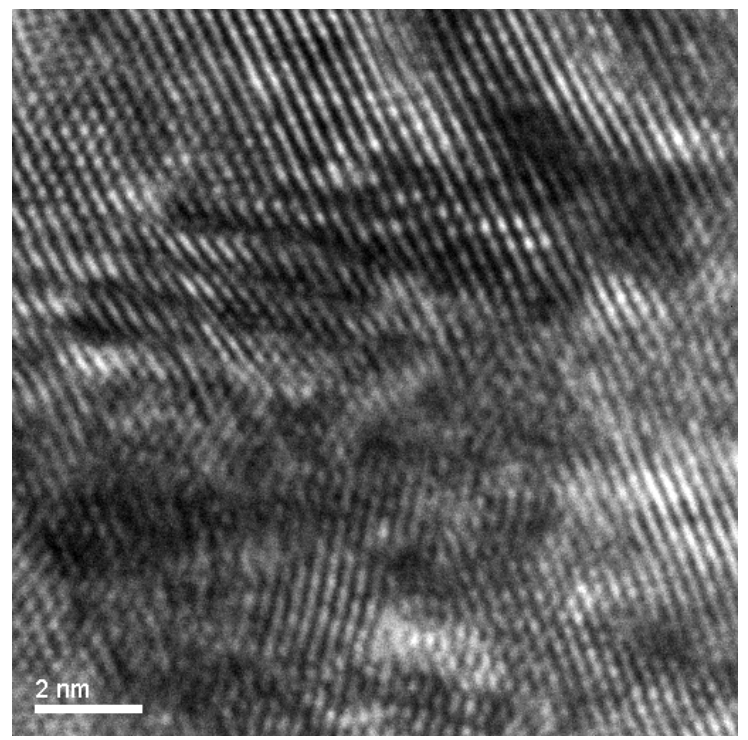

Fig.3. HREM showing dislocation defects.

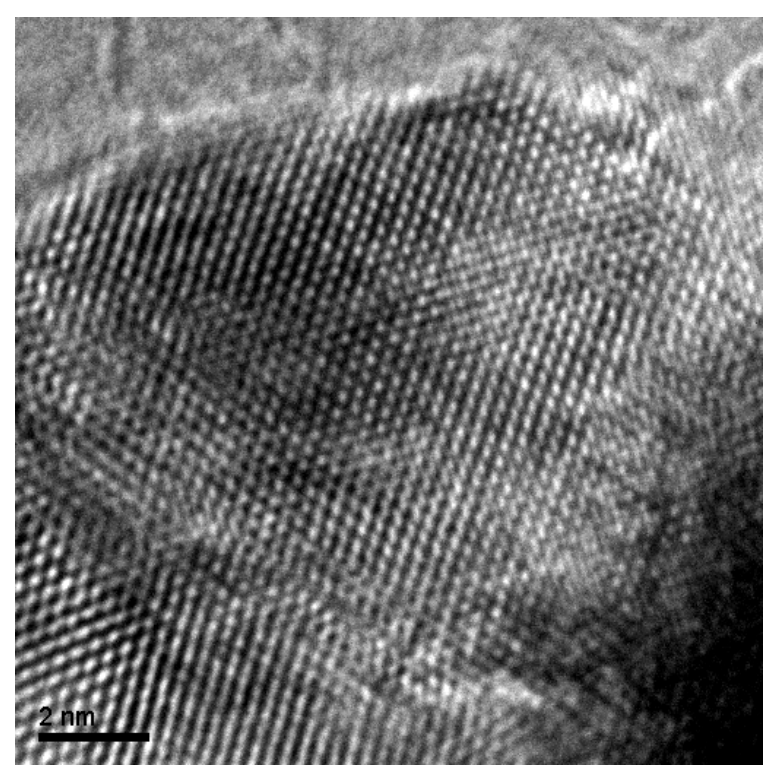

Fig.2. HREM image of nanocrystalline cluster.

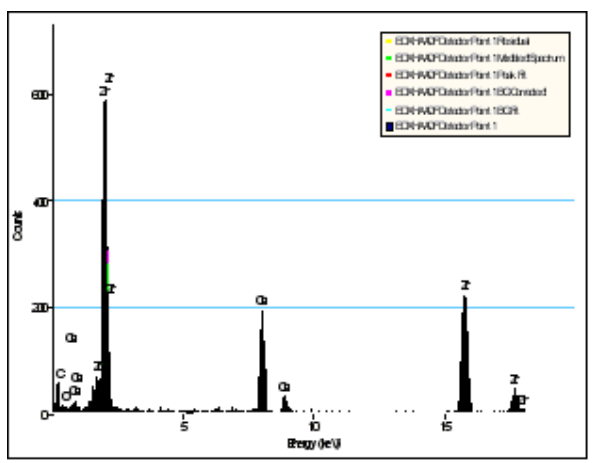

Fig.4. EDX microanalysis of $\mathrm{ZrO}_{2}$ nanocrystal. 